\title{
DEBATES
}

\section{Administração de conflitos e democracia: uma análise da página eletrônica do Conselho Nacional de Justiça}

\author{
Conflict resolution and democracy: an analisys of the National \\ Council of Justice web page
}

\section{Rafaela Selem Moreira \\ Roberto Fragale Filho}

\section{Resumo}

Este trabalho discute o lugar do poder judiciário, enquanto instituição política de relevância nacional, na promoção da democracia por meio de práticas de resolução de conflitos orientadas à autonomia e à emancipação cidadã da população. Vistas como alternativas à adjudicação, as práticas da mediação e a conciliação de conflitos surgem neste cenário como promessas de um novo paradigma de justiça. Em função do potencial democrático que lhe é atribuído, este estudo estabelece foco no procedimento de mediação. Como estas novas práticas, especialmente a mediação, são apropriadas política e ideologicamente no cenário institucional é a primeira análise deste trabalho. Como estas orientaçóes políticas institucionais são materializadas em programas institucionais e políticas públicas judiciárias na prática é a análise efetuada na sequência. A primeira análise tem como base a revisão da bibliografia e a legislação sobre o tema enquanto a segunda análise tem como base não apenas revisão bibliográfica, mas também, discursos, legislaçôes, matérias jornalísticas referenciadas na página eletrônica do Conselho Nacional de Justiça $(\mathrm{CNJ})$. Conclui-se que a institucionalização pasteuriza as práticas e reduz suas possibilidades emancipatórias à retórica.

\section{Palavras-chave}

Resolução de Conflitos; Mediação; Democracia; Ministério da Justiça; Brasil.

\begin{abstract}
The article discusses the role of the Judiciary as an institution in developing democracy through alternative conflict resolution practices. Such practices as Mediation and Conciliation are considered now in Brazil a possible new reference of Justice - a Justice of which the goal is citizens' emancipation and autonomy. This article focuses specifically on Mediation, because of its potential to improve democracy. The first part of the study describes how Mediation procedure is captured by political institutional speech. The second part of the study describes how this speech relates with judicial programs and public policies in this sense. Both analyses are based on bibliography review and national legislation. The second part also is based on speeches and articles published by the Ministry of Justice on its website in 2014. The analysis reveals that the institutionalization of these practices in official speeches makes real the possibility that "citizens' emancipation" becomes only political rhetoric.
\end{abstract}

\section{Keywords}

Conflict resolution; Mediation; Democracy; Ministry of Justice; Brazil. 


\section{Introducão}

Nas democracias legalmente estabelecidas em bases jurídicas e políticas liberais, a fórmula legitimadora do sistema legal não consiste na obtenção de consensos, mas no respeito unânime aos procedimentos formais decisórios (FARIA, 1989). A liberdade e a autonomia do indivíduo são garantidas pela efetividade jurisdicional do Estado. O poder judiciário tem assim, papel central na manutençáo da ordem democrática, uma ordem procedimental propícia à convivência da diferença e da divergência. Ocorre, no entanto que ao assumir esse papel, o Estado adentra conteúdos da esfera intima fazendo da economia uma questão privada, e do direito, um direito civil ${ }^{1}$. Em outras palavras, na aplicaçáo do ordenamento jurídico, o judiciário decide questóes intimas e privadas, forma opinióes, padroniza desejos, expectativas e reaçóes (FARIA, 1989). Diante desta conjuntura, questiona-se [o] que ocorre com o liberalismo jurídico-político diante da explosão de litigiosidade que, sob as mais variadas formas e os mais diversificados pontos de ruptura da ordem social, hoje caracteriza as sociedades de classe? (FARIA, 1989, p. 29). O modelo liberal jurídicolegal está chegando a um grau de exaustão cujo resultado de sua ineficiência não pode ser mais escamoteado. Salta aos olhos a incapacidade de o judiciário dar conta das demandas que a realidade lhe apresenta todos os dias.

Apesar de apregoada pelas corporaçóes de advogados, consagrada pelos tribunais e quase canonizada pelas escolas de direito, qual o futuro dessa cultura legalista, marcada pelas transgressôes de caráter coletivo envolvendo grupos, classes e comunidades com projetos éticos e sociais conflitantes? Embora enraizada nos círculos jurídicos, terá essa cultura alguma conformidade com a tensa realidade de um país estigmatizado pelas contradiçôes sociais, desigualdades econômicas e confrontos políticos de caráter classista? (FARIA, 1989, p. 161).

É nesse contexto que a linguagem (re)aparece como um importante instrumento não apenas para a compreensão mas, igualmente, para a modificação e transformação social, atuando como instrumento de resoluçáo de conflitos. Ganha espaço neste cenário a discussáo sobre a mediaçáo de conflitos como promessa para os sistemas jurídicos em democracias liberais em crise.

\footnotetext{
${ }^{1}$ Que consagra os princípios jurídicos da autonomia da vontade, da livre disposição contratual e o do clássico pacta sunt servanda.
} 


\section{Mediação e dialética da autonomia do encaminhamento de conflitos}

A mediação é um procedimento de administração de conflitos no qual a solução é construída dialeticamente pelas partes envolvidas por meio da moderação de um terceiro, o mediador. É papel de um mediador facilitar o diálogo comunicaçáo funcional entre pessoas - para a construçáo gradativa ${ }^{2}$ de um entendimento. Uma confusão comum existe entre os conceitos de mediação, conciliação e negociação. $\mathrm{Na}$ negociaçáo, as partes que vivem um conflito de interesses, negociam frente a frente com mútuas concessóes, uma situação benéfica para ambas, sem necessidade de um terceiro interventor. Ao contrário, nos demais procedimentos - mediação e conciliação - há a figura de um terceiro. No procedimento de conciliaçáo, o conciliador atua para promover o diálogo entre as partes, podendo fazer intervençóes com sugestóes. $\mathrm{O}$ conciliador busca ativamente $\mathrm{o}$ acordo apontando para possibilidades que as partes ainda não vislumbraram, ou que, por si sós não vislumbrariam. No procedimento de mediação é diferente. O mediador não apresenta sua opinião sobre o conflito, tendo por função auxiliar as partes a chegarem a uma comunicação funcional, por meios de estratégias de comunicação perguntas, resumos e paráfrases ${ }^{3}$. Deter-nos-emos, mais especificamente neste último procedimento, a mediação, em função do potencial democrático de promoção da cidadania que alguns estudiosos (CHILTON e CUZZO, 2005; MENDONÇA, 2006; MOREIRA, 2009) a ela atribuem.

\section{Dialética da autonomia e seu potencial democrático}

Especialistas no procedimento de mediação sustentam sua aplicação ancorada em padrôes éticos, verdadeiros princípios do procedimento: “[a] auto-determinação

\footnotetext{
${ }^{2}$ A palavra "gradativa" deve ser entendida como oposto de "instantânea". Não se trata de um acordo construído em um único ato de entendimento, como o caso de uma decisão judicial, mais construído com base em acordos comunicacionais que vão se estabelecendo ao longo do processo dialético.

${ }^{3}$ De acordo como o tipo de reflexão que o mediador quer gerar, pode fazer uso de perguntas fechadas - de resposta sim ou não -, perguntas abertas - que podem ter desenvolvimento discursivo amplo, e ainda resumos e paráfrases. $\mathrm{O}$ resumo expressa a capacidade de síntese do mediador. Em outras palavras, é a capacidade de identificar os pontos chaves que para as partes são importantes de serem discutidos. É uma devolutiva sintética para as partes do que elas mesmas falaram. A paráfrase é outra técnica de comunicação na qual o mediador reproduz fielmente o discurso de uma das partes ou de ambas, para se certificar de que entendeu o que foi dito. Elementos subjetivos como julgamentos e críticas são extraídos do discurso e substituídos por percepçóes de sentimento. Ao invés de repetir "o que o outro fez é inadmissível" o mediador pode parafrasear como "para você foi muito frustrante a atitude do outro?” São ferramentas para auxiliar as partes a ampliar suas percepções sobre si mesmas e sobre o conflito.
} 
das partes, a imparcialidade e competência do mediador, a informalidade e a confidencialidade do processo são princípios definidores da mediação" (MENDONÇA, 2006 , p. 25). Neste sentido, destacamos o princípio da autodeterminação, pois diz respeito à capacidade das partes de elaborarem de forma racional uma tomada de decisão. A força vinculante da decisão estaria apoiada na efetividade dialética - tópico retórica ${ }^{4}$ - implementada ao longo do processo comunicacional. Em outras palavras, quando as partes dialogam a partir de pontos comuns e, ao longo da conversa, seguem construindo, dentro da "lógica do razoável", novos pontos comuns, até a culminância de uma decisão final que encerra o conflito, esta última, por si só, não é mais uma intervenção adjudicada alienígena ou artificial a ser acatada, mas uma nova ordem relacional legitimamente construída pelas próprias pessoas envolvidas no conflito.

Com essa ênfase nos valores, a tópica chama atenção para o fato de que a efetividade do direito não toma por base, apenas, a coercitividade que acompanha as decisóes judiciais, mas também a adesão voluntária dos jurisdicionados, provocada pela força dos melhores argumentos (SOUZA NETO, 2001, p. 86-87).

Por estar promovendo adesão de comportamentos com base na autonomia da vontade, a mediação teria um compromisso direto com o ideal democrático de autonomia, emancipação e cidadania ${ }^{5}$. Seria a mediaçáo uma promessa para o futuro das políticas judiciárias?

\footnotetext{
${ }^{4}$ A partir de topois, tópicos ou simplesmente lugares comuns, verdadeiras premissas de ordem comum entre os envolvidos no conflito, são fundados os valores e hierarquias que nortearáo o processo comunicacional.

${ }^{5}$ As praticas comunicacionais que consubstanciam a mediação foram percebidas à luz a teoria da ação comunicativa (HABERMAS, 2003) enquanto ferramentas potentes na promoção de democracia. Este procedimento aplicado em larga escala proporcionaria uma sociedade mais desperta e engajada com suas responsabilidades ao ter cidadãos constituintes dos processos aos quais estariam submetidos, e não apenas expectadores (MENDONÇA, 2006). A teoria da ação comunicativa de Habermas busca um conceito comunicativo de razão e um entendimento de sociedade onde os indivíduos participam ativamente das decisóes individuais e coletivas de forma consciente, ou seja, com responsabilidade sobre suas decisóes. De acordo com essa teoria, o indivíduo é visto como um ente participativo que, antes de agir, avalia as possíveis consequências de seus atos, tendo em vista, por exemplo, as sançóes que a um determinado ato seu poderiam ser aplicadas. A argumentação entre os indivíduos é o meio utilizado para buscar o entendimento entre eles, sendo justamente por meio da argumentação racional que os indivíduos procuram convencer uns aos outros da veracidade de suas afirmaçóes e declaraçóes, bem como da validade ou não de uma norma. Esse tipo de participação social em espaços públicos fortalece a sociedade
} 


\section{A mediação no cenário das políticas públicas judiciárias}

A mediação foi uma iniciativa que veio, desde a década de 1970, ganhando espaço na esfera legal como alternativa à lógica da adjudicação (DAVIS, 2001). Seu sucesso nos Estados Unidos foi grande, a ponto de levar à sua difusão por outros países. No Brasil, por exemplo, o uso da mediação vem ganhando especial relevância para o judiciário. Em 1996, o Banco Mundial publica relatório com questôes latentes a um melhor funcionamento do sistema judiciário não apenas no Brasil como em toda América Latina e Caribe (DAKOLIAS, 1996). No aspecto do acesso à justiça o relatório aponta como inadmissíveis processos com duração de dez anos, e considera mecanismos alternativos de resoluçáo de conflitos como elementos constituintes de uma reforma deste sistema ineficiente. A proposta de criaçáo de um Conselho de Justiça também é apontada neste estudo.

Nos anos 80, a estabilidade econômica chega à realidade de muitos países que, como o Brasil, passam a trabalhar buscando a equidade social, bem como as reformas políticas e econômicas. Este momento histórico é propício ao chamado conjunto de reformas de segunda geração, as reformas institucionais, entre estas, o judiciário.

Para aplicar e interpretar as leis de forma igualitária e eficiente o que significa que deve existir: a) previsibilidade nos resultados dos processos; b) acessibilidade as Cortes pela população em geral, independente de nível salarial; c) tempo razoável de julgamento; d) recursos processuais adequados (DAKOLIAS, 1996, p. 29).

Neste sentido, apresenta na qualidade de mecanismos para minimizar obstáculos de acesso à justiça, e consequentemente, a potencializar a confiança no judiciário, os chamados MARC (Mecanismos Alternativos de Resolução de Conflitos). No relatório em questão, estes são apresentados da perspectiva da alternativa ao sistema formal e não como integrantes do sistema formal. Em outras palavras, para quem quer evitar o judiciário, fugir da judicialização, os "MARC podem proporcionar às partes métodos alternativos de resolução amigável de conflitos, distante da morosidade do sistema formal" (DAKOLIAS, 1996, p. 40).

No Brasil, desde o início da última década, os MARC começam a ser incorporados no contexto do sistema formal de justiça. Nas varas de família e juizados especiais, antes de qualquer audiência de instruçáo e julgamento, era agendada uma

civil e expressa a democracia. Dessa maneira, a paz passa a contar com um instrumento para sua concretização. Não apenas a paz como ausência de violência física, mas também a paz como a efetivação de direitos fundamentais (SALES, 2003). 
conversa "conciliadora" entre as partes. Além de ser um meio dos participantes buscarem uma solução fora da lógica vencedor/vencido, típica da adjudicação, a mediação era percebida como importante e eficiente instrumento de acesso à justiça ${ }^{7}$. No Brasil, argumentava-se quanto aos MARC que esses procedimentos constituíam estilo mais acessível do que os procedimentos formais de adjudicaçáo. O perfil informal da mediação, por exemplo, permitiria aos envolvidos dialogarem suas questôes com um discurso próximo de suas realidades, não legalista, e descontraído. Segundo Davis (2001), este seria um dos principais motivos para menor utilização desse procedimento no âmbito do judiciário: juízes e promotores, treinados para o discurso técnico jurídico, não perceberiam com bons olhos construçóes não jurídicas com força coercitiva. Em outras palavras, se para as partes a mediação poderia gerar maior satisfação, para os agentes oficiais da instituição judiciária, o discurso da mediação seria inapropriado. Pelo mesmo motivo que nos juizados especiais - criados para o acesso a direitos de forma célere - ainda que não haja necessidade de advogado, dificilmente o cidadáo seria capaz de sozinho formular seu pedido dentro dos mínimos requisitos processuais, a mediação no contexto do judiciário também tem sido muito criticada.

Owen Fiss (2004) é uma referência bibliográfica crítica à mediação: é radicalmente contrário à ideia do acordo. Sua crítica é direcionada ao movimento chamado ADR (Alternative Dispute Resolution) nos Estados Unidos. Seu argumento estaria centrado em diferentes aspectos do método proposto na mediação: "Não acredito que o acordo, como prática genérica, seja preferivel ao julgamento ou deva ser institucionalizado em uma base extensa e ilimitada" (FISS, 2004, p. 123). Isto por que no mundo real, seria preciso considerar a desigualdade de poder e forças que desequilibra relaçóes interpartes. Qualquer consentimento obtido através de um procedimento de mediaçáo que náo possui meios de equilibrar relaçóes de força entre partes, contaria com elemento de coação de uma parte em relação à outra - o acordo seria injusto e ilegal.

\footnotetext{
${ }^{6}$ A confusão entre os conceitos de mediação e conciliação no judiciário não é algo recente. Desde que práticas alternativas à adjudicação começaram a ganhar espaço na instituição, mediação e conciliação foram tratadas como sinônimas, sendo, anos depois, diferenciadas oficialmente (AZEVEDO, 2009). Mesmo assim, ainda hoje, nos canais de comunicação do judiciário, como o sitio do Conselho Nacional de Justiça, ainda verificamos esta confusão.

${ }^{7}$ As partes têm controle sobre o processo decisório, aumentando a concordância e o cumprimento da decisão final (DAVIS, 2001).
} 
[A] transação pode ser realizada por alguém que não possui autoridade; a ausência de instrução processual e de julgamento cria um subseqüente e problemático envolvimento do juiz; e embora os dockets [casos judiciais,] sejam abreviados, a justiça pode não ter sido feita (FISS, 2004, p. 124).

Entre elementos que desequilibram a relação e viciam o acordo estaria a disparidade de recursos financeiros entre as $\operatorname{partes}^{8}$. Se a disparidade de recursos entre as partes influencia um procedimento judicial, podendo distorcer seus resultados, na mediação, teria efeitos mais desastrosos (FISS, 2004). Em outras palavras, a mediação não contaria com a figura do "juiz" e sua competência para minimizar as desigualdades entre as partes". Por fim, menos do que a sensação de justiça, o acordo [teria apenas gerado] o alivio por ter evitado a "agonia do julgamento" (FISS, 2004, p. 141).

No mesmo ano que Davis (2001) apresenta os benefícios da mediaçáo, no Brasil, é iniciado com a liderança do juiz estadual André Gomma de Azevedo, um grupo de estudos ligado à Faculdade de Direito de Brasília (FD/UNB) para desenvolver no país o tema da mediação com foco no seu uso pelo poder judiciário ${ }^{10}$.

\footnotetext{
${ }^{8}$ A parte mais pobre muitas vezes não tem meios de reunir e analisar as informaçóes necessárias à previsão da decisão do litígio, ela poderia ingressar em procedimento de negociaçáo em desvantagem com relação a uma parte que teria essa visão; Uma parte pobre não teria ainda recursos para esperar o trâmite de um processo judicial e na ânsia pela rápida a satisfação de sua necessidade, poderia optar por um acordo injusto - submetendo-se, por exemplo, a uma indenização inferior à que realmente lhe seria devida; A parte mais pobre não teria nem o montante necessário para propor uma ação, podendo aceitar um acordo insatisfatório ou injusto por falta de alternativa (FISS, 2004).

9 Segundo Fiss (2004), o acordo seria ainda mais "nebuloso" quando realizado por organizaçáo autonomeada representante dos interesses de um determinado grupo. A formulaçáo do acordo acabaria sendo feita por quem não tem autoridade para exercê-la, como acontece com acordos envolvendo grupos difusos. A legitimidade deste "grupo de representantes" perante seus "representados" seria questionável. Desse modo, não teria autoridade para firmar acordos capazes de submeter à coletividade que supostamente representa. Ademais, os juízes tenderiam a homologar mais facilmente os acordos mais próximos do que eles mesmos decidiriam se naquele caso proferissem sentença (FISS, 2004), apesar de no procedimento de homologação não haver julgamento completo do caso, não havendo, portanto, ampla instrução probatória. Por ser o procedimento judicial comumente um procedimento continuado - ou seja, de um divórcio desdobram-se discussóes sobre alimentos, guardas de filhos etc. -, esses outros processos seriam prejudicados por náo ter havido no primeiro um julgamento completo. Uma discussão para modificação de um acordo obrigaria o juiz a voltar no tempo, analisar a situação no momento da ratificação do acordo para decidir, por fim, se cabível seria sua revisão.

10 Mello e Baptista (2011) fazem referência ao juiz e professor André Gomma de Azevedo como responsável pelos primeiros treinamentos em mediação no TJRJ e ainda descrevem detalhadamente sua formação, conectando-a, curiosamente com a foto de capa do manual de mediação do judiciário. Uma imagem que está em Nova Iorque - local onde André Gomma de Azevedo cursou parte de sua
} 
As atividades deste grupo culminarão, oito anos depois, em 2009, na publicação do primeiro Manual de Mediação Judicial chancelado pelo Conselho Nacional de Justiça $(\mathrm{CNJ})^{11}$. Por ocasião do lançamento deste trabalho, o Ministro da Justiça Tarso Genro reconheceu que questóes apontadas por Fiss (2004) precisam ser ponderadas e colocou o desafio da "Mediaçáo Judicial" enquanto política pública judiciária:

Há tempos, busca-se desenvolver meios de resolução de disputas que se realizem sem a imposição do poder do mais forte ou sem uma norma positivada que desconsidera a participação direta do usuário na soluçáo. Atualmente, esse é um dos primordiais desafios da Justiça: desenvolver procedimentos que sejam considerados justos pelos próprios usuários, não apenas em razão dos resultados, mas também em função da forma de participação no curso da relação jurídica processual (AZEVEDO, 2009, p. 106).

Neste sentido, a mediação de conflitos chega institucionalmente ao judiciário brasileiro, pela pauta política do CNJ.

\section{Um Judiciário orientado à democracia: a mediação no discurso oficial do CNJ}

Em 2009, o Ministro da Justiça, Tarso Genro, informou que a mediação seria recebida no cenário nacional com cautela, mas também com entusiasmo. Este entusiasmo foi compartilhado pelo Secretário de Reforma do Judiciário, Rogério Favreto, que anunciou a implantação da mediação como política pública nacional (AZEVEDO, 2009). Favreto informou naquele momento que o foco era o aprimoramento de projetos pilotos no Brasil a partir de mecanismos de aferição de efetividade. De fato, não existia ainda uma política pública nacional, apenas uma

formação - na sede da ONU e foi um presente da Rússia aos Estados Unidos, cujo simbolismo é o de transformar espadas em arados. Uma mudança de perspectiva da lida com os conflitos. Ao falar dos primeiros cursos de mediaçáo em tribunais os autores informam: "No estado do Rio de Janeiro, o primeiro curso de mediação de conflitos oferecido no Tribunal de Justiça, realizado em janeiro de 2009, culminou na inauguração, em 10/12/2009, do Centro de Mediação do Fórum Central do Tribunal de Justiça do Rio de Janeiro. Ele é um bom ponto de partida para se pensar questóes importantes a respeito da atuaçáo de mediadores no Judiciário, assim como os diversos sentidos e sensibilidades sobre justiça, direitos e cidadania que se revelam nessa prática, colocando em interação atores, saberes e visões de mundo" (MELLO e BAPTISTA, 2011, p. 101).

11 "O Conselho Nacional de Justiça (CNJ) a é uma instituição pública que visa aperfeiçoar o trabalho do sistema judiciário brasileiro, principalmente no que diz respeito ao controle e à transparência administrativa e processual. Criado em 31 de dezembro de 2004 e instalado em 14 de junho de 2005, o Conselho tem sua sede em Brasília, mas atua em todo o território nacional” (WIKIPEDIA, 2014). 
intenção de tê-la. A palavra "aprendizado" era repetida diversas vezes pelos secretários (AZEVEDO, 2009). Entre os aspectos de sucesso para um programa de mediação, foram destacadas variáveis a serem consideradas como: (1) necessidades das partes envolvidas, (2) especificidades da questão em debate e (3) qualidade do programa de formaçáo de mediadores. A mediação era defendida em um contexto maior - a perspectiva de construção de um judiciário democrático, efetivo, solidário e humanizado. Acreditava-se que a mediação tinha potencial para tanto ao trazer o usuário do sistema de justiça para participar da decisão. Isto seria "um caminho irreversível para democracia” (AZEVEDO, 2009). Favreto acreditava que o usuário dos serviços judiciais tinha maior satisfação com o devido processo legal quando sua participação no mesmo aumentava. Neste sentido, também acreditava que a sensação de realização da justiça aumentava tanto quanto maior a participaçáo deste mesmo usuário na escolha dos processos para dirimir suas questóes. Em discurso, Favreto sugeria que, enquanto a mediaçáo - como projeto de política pública - estivesse em "fase de testes", o foco do judiciário deveria estar na formação dos mediadores e de um "procedimento modelo" de mediação judicial. Para tanto, os secretários do Ministério da Justiça e da Reforma do Judiciário incentivavam os tribunais brasileiros a adotar iniciativas de treinamento de mediadores e de oferta de serviços gratuitos de mediação ${ }^{12}$. Um ano após estas declaraçôes, em 2010, com base no princípio da eficiência operacional e responsabilidade social ${ }^{13}$, é editada a resolução 125 do $\mathrm{CNJ}$.

12 "Neste sentido, a Secretaria de Reforma do Judiciário Ministério da Justiça incluiu, no Programa Nacional de Segurança Pública com Cidadania (PRONASCI) os cursos de capacitação dos operadores do Direito, priorizando o conhecimento e a prática das técnicas de mediação e de conciliação judicial. Nesta açáo, incorporou-se a Escola Nacional de Aperfeiçoamento e Formação da magistratura (ENFAM), viabilizando parceria com o Ministério da Justiça na realização e financiamento de cursos de formação de multiplicadores em mediação para magistrados federais e estaduais, bem como diversos convênios com escolas regionais da magistratura [...]. Também foram firmadas parcerias para capacitação de membros do Ministério Público, defensores públicos e advogados. [...] [tendo em vista] constituir um novo paradigma cultural por intermédio de cursos de aperfeiçoamento aos operadores jurídicos. [...] Em função disso que a ação do Ministério da Justiça volta-se também para a formação futura dos bacharéis, por meio do projeto "Pacificar" que financiou 17 núcleos de práticas jurídicas em 2008 e mais 13 em 2009, através da seleçáo de propostas enviadas pelas Faculdades de Direito. [...] Merece ainda um breve registro o projeto "Justiça Comunitária" que integra esse esforço de pacificação a partir da implantação de núcleos nas comunidades para empoderamento social pela formação em direitos e capacitação de agentes comunitários de mediação". Rogério Favreto, Secretário de Reforma do Judiciário (AZEVEDO, 2009, p. 19).

${ }^{13}$ Ambos estabelecidos como objetivos estratégicos do poder judiciário na resolução do CNJ no 70 de 2009. 
Esta resolução institui a política judiciária nacional para tratamento dos conflitos e detalha o papel da mediação e conciliação neste cenário.

\section{Resolução 125 do CNJ: uma política de tratamento humanizado aos conflitos}

Segundo o texto da resolução 125 do $\mathrm{CNJ}$, os conflitos deveriam ter diferentes tratamentos conforme suas respectivas naturezas e peculiaridades (SALES e ANDRADE, 2011). Ao publicar esta resoluçáo, em 2010, o CNJ trazia para si a competência de organizar um programa judicial de conciliação e mediação a partir de um trabalho em rede, junto às universidades e sociedade civil ${ }^{14}$.

Entre as inovaçóes da resolução estão desde o estabelecimento de conteúdo mínimo programático para formação de mediadores ao código de ética dos conciliadores e mediadores judiciais (MELLO e BAPTISTA, 2011). A disseminação da cultura de práticas autocompositivas também seria um eixo central deste ato normativo: os tribunais ganharam um prazo - que variava de 30 dias a um ano dependendo do Tribunal - para criar "Núcleos Permanentes de Métodos Consensuais de Solução de Conflitos" vinculados ao $\mathrm{CNJ}^{15}$, bem como treinar suas equipes de servidores para operá-los conforme conteúdo programático e código de ética.

A preocupação com indicadores de resultados também é tópico desta resolução que determina a necessidade dos tribunais criarem e manterem banco de dados sobre as atividades destes "Núcleos". O trabalho de compilar, avaliar e planejar os rumos desta política caberia ao próprio CNJ. Sob sua responsabilidade ficaria também a criação do "Portal da Conciliação e Mediação" que seria disponibilizado ao

\footnotetext{
${ }^{14}$ Dois anos após a resolução ser publicada, é criada no âmbito da Secretaria de Reforma do Judiciário a "Escola Nacional de Mediação e Conciliação", por ato do Ministro da Justiça. O público para o qual os cursos são oferecidos é de operadores de direito. Tendo em vista a garantia de amplo acesso, os cursos são gratuitos e a distância, operados a partir do Centro de Educação à Distância (CEAD) na UNB, com participação do departamento de pedagogia. Os cursos começam a ser operados em 2013 sob a supervisão de advogados e juízes com qualificação na área da mediação. Os cursos ofertados atualmente são: (1) Mediação (genérico); (2) Mediaçáo Empresarial; (3) Mediação em conflitos envolvendo a administração pública, sob coordenação da procuradora Luciana Moessa e (4) mais recentemente, em meados de 2014, também o curso de mediaçáo comunitária - este último sob coordenação da juíza do TJDFT, Glaucia Foley.

${ }^{15}$ Em janeiro de 2013, com a intenção de acelerar o processo de consolidação da mediação enquanto política pública nacional, o CNJ emendou a resolução 125/2010 para estabelecer prazo para os tribunais "em 60 (sessenta) dias, [criarem] os Núcleos Permanentes de Métodos Consensuais de Solução de Conflitos, compostos por magistrados da ativa ou aposentados e servidores".
} 
público no sítio virtual do CNJ. A ideia era reunir neste local as diretrizes da capacitação de conciliadores e mediadores e seu código de ética, os relatórios gerenciais do programa de Núcleos Permanentes por unidade judicial e o compartilhamento de boas práticas, projetos, ações, artigos, pesquisas e outros estudos no tema. O CNJ deveria manter, assim, um fórum permanente de discussão com a participação da sociedade civil.

Neste contexto, enquanto Sales e Andrade (2011) enfatizam em tom de crítica a responsabilidade - ou irresponsabilidade - dos bancos universitários neste processo $^{16}$, Mello e Baptista (2011) desaprovam a falta de participaçáo do jurisdicionado na escolha dos mecanismos que poderiam gerar celeridade processual ${ }^{17}$ e oferecem como exemplo deste cenário o Movimento pela Conciliação, como veremos a seguir no próximo tópico, uma análise do website do CNJ.

\section{Comunicação institucional da implementação de uma politica pública - o website do CNJ}

Conforme vimos, a resolução 125 anunciava a criação de um "Portal da Conciliação e Mediação" no sítio virtual do CNJ. O ato normativo previa uma construção gradativa, observadas as possibilidades técnicas da instituição. Desde então, quatro anos se passaram e em julho de 2014 avaliamos os avanços institucionais do Judiciário neste sentido. Para tanto, realizamos uma revisão bibliográfica, exploramos o website do $\mathrm{CNJ}$ e descreveremos neste tópico, alguns pontos de observação de "destaque"18.

Quando um cidadão acessa o website do CNJ, encontra inicialmente "link" para informaçóes sobre (1) o CNJ, (2) a presidência e (3) a corregedoria, (4) os atos normativos, (5) os "programas de A à Z", (6) sistemas e (7) arquivos multimídia. Além destes, matérias de destaque ocupam a página inicial na forma de chamadas fixas $^{19}$ e dinâmicas ${ }^{20}$. As notícias do website dão destaque àquilo que o $\mathrm{CNJ}$ quer

\footnotetext{
${ }^{16}$ Segundo os autores Sales e Andrade (2011) a morosidade do judiciário e sua necessidade de reforma muito se deve ao fato das universidades não saberem ensinar a operar as formas alternativas de tratamento dos conflitos adequadamente.

17 "Mas parece que estas medidas objetivam exclusivamente celeridade e, com isso, olvidam-se de outros fatores importantes para o jurisdicionado. Este, inclusive, não teve participaçáo na escolha institucional (e unilateral) da celeridade como pauta atual dos tribunais" (MELLO e BAPTISTA, 2011, p. 120).

${ }^{18}$ Consideramos pontos de destaque, selecionados para ilustrar este artigo, aqueles que apresentam sinergia com a discussão do acesso e democratização da justiça via participação popular, em especial, às práticas alternativas à adjudicação - Mediação e Conciliação.

${ }^{19}$ Em formato semelhante ao da página inicial de um jornal virtual.
} 
comunicar ao grande público. Por meio de uma análise coordenada de notícias e conteúdos de links, foi possível inferir os assuntos de maior relevância para o Judiciário no momento de nossa pesquisa ${ }^{21}$.

\section{CNJ - "Serviços ao Cidadão"}

Ainda na página inicial do $\mathrm{CNJ}$, chamou-nos a atenção um quadro denominado "Serviços ao Cidadão" - uma interlocução direta entre CNJ e cidadão que aparentemente poderia haver sinergia com nossa pesquisa. Ao acessar este link, notamos que a maior parte dos conteúdos não consubstanciava serviços ofertados diretamente pela instituição ao cidadáo, mas informaçôes sobre práticas administrativas gerenciais do judiciário. Em outras palavras, eram conteúdos sobre o dia-a-dia gerencial da própria instituição ${ }^{22}$. Além destes aspectos administrativos, outros conteúdos não administrativos também estavam disponíveis em forma de tópicos neste link. O primeiro deles é o acervo de publicaçôes institucionais. Dezenas de publicaçóes do CNJ embaladas pelo título "biblioteca CNJ" são apresentadas nesta área. Outro é o conteúdo apresentado sob o título "Informação". Destacamos aqui este tópico, pois seu conteúdo não conduz o leitor ao encontro de qualquer informação institucional, mas a descrição sobre o direito do cidadão ao acesso à informaçáo baseado na lei n. 12.527 de 2011. Este fato nos remeteu às análises de Holston (2013) quanto ao engajamento cidadáo brasileiro em processos de mudança - administramos mudanças legalizando os aspectos sociais que queremos ver materializados. Esta forma de garantir um serviço de informação - indicando a existência de uma lei - sugere a ratificação desta percepção legalista de garantia de direitos.

Seguindo nossa análise, restaram ainda os seguintes tópicos: (1) "Como acionar o CNJ"; (2) localização de cartórios extrajudiciais no Brasil e (3) a lista de

\footnotetext{
${ }^{20}$ Expostas de forma mais dinâmica, com cinco chamadas ilustradas que se substituem, dando mais interatividade à comunicação com o leitor.

${ }^{21}$ No que tange às políticas públicas judiciárias, em julho de 2014, é possível aferir o especial interesse do Judiciário em políticas para infância e adolescência Enquanto uma chamada fixa para matéria anunciava: "Corregedoria recomenda prioridade nos julgamentos de casos de abuso e tortura contra crianças", no letreiro dinâmico, duas chamadas ilustradas também apresentavam ao leitor duas matérias afins: (1) "Oferta de capacitaçóes especiais para tomada de depoimento de crianças" e (2) "Visita do CNJ em Centro de Reabilitação de Menores em um estado brasileiro."

${ }^{22}$ Exemplo disto é a apresentação de conteúdos sobre (1) produtividade dos servidores, (2) concursos públicos para composição de quadros de servidores, (3) transparência na prestação de contas com notícias sobre medidas financeiras e administrativas m curso e (4) agenda CNJ de eventos internos como treinamentos e seminários entre outros, não necessariamente abertos ao público.
} 
contatos das Defensorias Públicas. Considerando que a lista de cartórios extrajudiciais e de contatos de defensorias públicas estão disponíveis em outros sites, analisaremos o serviço "acionar o CNJ" enquanto único serviço stricto senso ofertado pelo CNJ diretamente ao cidadão.

Quando acessamos o conteúdo "Acionar o CNJ", recebemos a informação que qualquer cidadão pode acionar o $\mathrm{CNJ}$, mesmo sem advogado. $\mathrm{Na}$ sequência, encontramos o procedimento através do qual isto deve ser feito. A explicaçáo faz remissão a portarias, leitura de guias e manuais para preenchimento de pré-requisitos. O "peticionamento" é eletrônico. Além de todo o conhecimento procedimental, o cidadão precisaria de uma leitora de "cartão/token" - seja lá o que isso signifique. Considerando que o Brasil é um país onde, segundo o IBGE, menos da metade da população tem acesso à internet - contabilizado no percentual de digitalmente incluídos aqueles que acessam a internet via lanhouse, escolas e bibliotecas - e que estados do norte e nordeste como Maranhão (24,1\%), Piauí $(24,2 \%)$ e Pará $(30,7 \%)$ apresentam números ainda inferiores de inclusão digital, é possível inferir que o acesso ao $\mathrm{CNJ}$ não é fácil ao cidadáo brasileiro médio. Este fato nos chama a atenção, quando o tomamos da perspectiva do acesso à justiça e democratização enquanto diretrizes institucionais do nosso judiciário.

\section{CNJ - "Acesso à Justiça”}

Considerando o foco do Judiciário em promover eficiência e democratização de serviços por meio de formas alternativas de resoluçáo de conflitos, pesquisamos conteúdos correlacionados à mediação e conciliação. Em julho de 2014, não havia no Portal do CNJ qualquer referência a programas e projetos de mediaçáo. No link "Programas de A à Z"23 encontramos a opção de acessar o conteúdo que o CNJ elaborou para o tema "Acesso à Justiça". Passamos a interface de "Acesso à Justiça” e encontramos a seguinte orientação política "Objetiva acelerar a tramitação dos processos na Justiça. A proposta é facilitar o acesso ao Judiciário e garantir a razoável duração dos processos judiciais" ${ }^{24}$. O que vemos neste ambiente virtual é o substancial destaque às práticas de conciliação - nada é falado sobre a mediação.

\footnotetext{
${ }^{23}$ Os programas que o $\mathrm{CNJ}$ apresenta no website sob o "guarda-chuvas" de "Programas de A à Z" são: (1) acesso à justiça; (2) assuntos fundiários; (3) direitos humanos; (4) eficiência, modernizaçáo e transparência; (5) formação e capacitação; (6) infância e juventude; (7) judiciário na copa; (8) mulher; (9) saúde e meio ambiente; (10) sistema carcerário e execução penal; (11) sistemas.

${ }^{24}$ Para mais informaçóes consultar CNJ (2014).
} 
Figura 1 - Website do CNJ, interface "Acesso à Justiça" no caminho: Página Inicial> Programas de A à Z> Acesso à Justiça

$\leftarrow \rightarrow$ C Www.cnj.jus.br/programas-de-a-a-z/acesso-a-justica

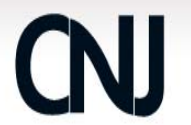

Faça sua busca

Pesquisa avancada Engish Espaío

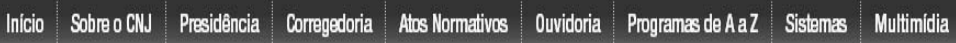

Páaina Inicial , Programas de A a Z + Acesso à Justiça

Acesso à Justiça

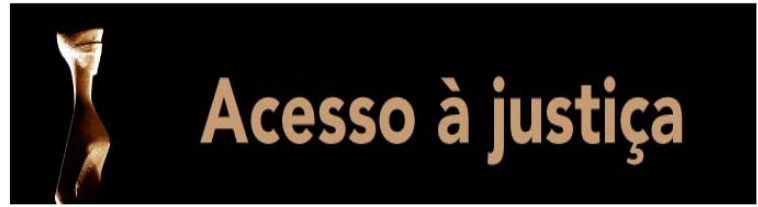

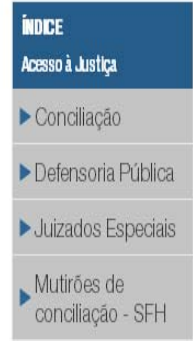

Esta área contém os programas coordenados pelo CNJ que objetivam acelerar a tramitaç̧áo dos processos na Justiça. A proposta é facilitar o acesso ao Judiciário e garantir a razoável duraçăo dos processos judiciais.

Fonte: CNJ, 2014.

A conciliação, e não mais a mediação, passa a figurar como a principal ferramenta para promoção do acesso à justiça no âmbito do poder judiciário ${ }^{25}$. Para o $\mathrm{CNJ}$, a conciliação seria um meio simplificado, eficaz, rápido e satisfatório de resolver uma demanda jurídica.

\footnotetext{
${ }^{25}$ Segundo a ministra Ellen Gracie, ao implantar o "Movimento pela Conciliaçáo” em agosto de 2006, o CNJ "teve por objetivo alterar a cultura da litigiosidade e promover a busca de soluçóes para os conflitos mediante construção de acordos" (MELLO e BAPTISTA, 2011, p. 100). No entanto, tanto a ministra quanto o conselheiro Joaquim Falcão criticam a sua forma de implementação pelos tribunais. Segundo eles, a fase de conciliação em geral não é suficientemente enfatizada pelos juízes, comprometidos com a cultura jurídica atual de justiça imposta e não produzida pelas partes. Superar esse traço cultural, de acordo com a propaganda do movimento, parece se constituir parte fundamental de uma estratégia para desafogar o Judiciário e lhe dar mais celeridade, bem como tornar a sociedade mais "pacífica". "Porém, pela observação de uma audiência conciliatória em uma das 50 Varas Cíveis do Tribunal de Justiça do Rio de Janeiro, verificamos que o discurso não é compatível com a prática. As partes, em geral, sequer comparecem à audiência, sendo representadas por seus advogados, que, através de procuração, manifestam terem poderes para transigir. Mas, de fato, em geral, não chegam a um consenso, até mesmo porque quando desejam efetivamente entrar em acordo, fazem-no extrajudicialmente, em seus respectivos escritórios, e levam ao juiz a petição do acordo já efetivado para mera homologação" (MELLO e BAPTISTA, 2011, p. 109).
} 
Figura 2 - Website do CNJ, interface "Acesso à Justiça" no caminho: Página Inicial> Programas de A à Z> Acesso à Justiça> Conciliação> Campanhas

$\square$ www.cnj.jus.br/programas-de-a-a-z/acesso-a-justica/conciliacao/campanhas

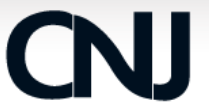

Faça sua busca

Pesquisa avançada

\begin{tabular}{|l|l|l|l|l|l|l}
\hline Início Sobre o CNJ Presidência Corregedoria Atos Normativos Ouvidoria & Programas de AaZ Sistemas Multimídia
\end{tabular}

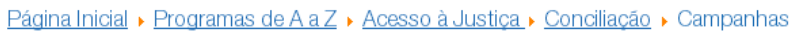
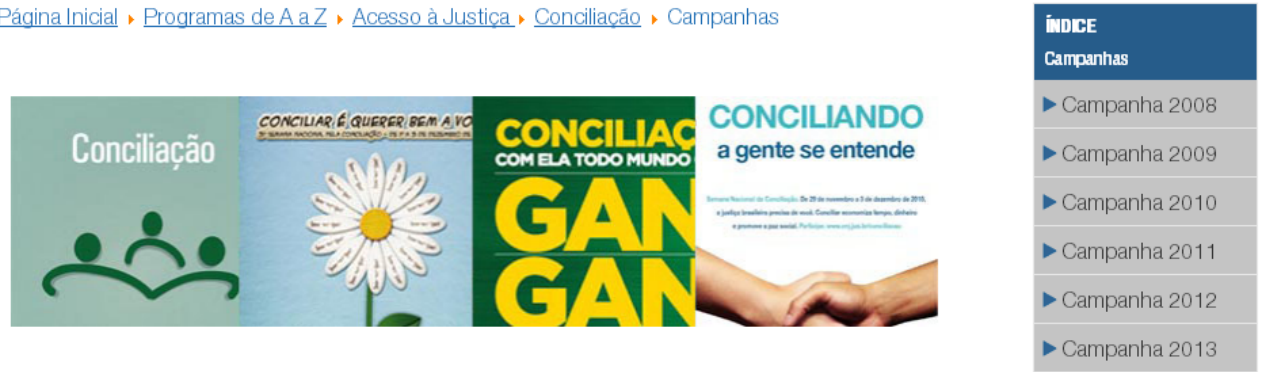

O objetivo das campanhas desenvolvidas pelo Conselho Nacional de Justiça em parceria com os tribunais participantes do movimento pela conciliação é disseminar em todo o país a cultura da paz e do diálogo, desestimular condutas que tendem a gerar conflitos e proporcionar às partes uma experiência exitosa de conciliaçăo.

Fonte: CNJ, 2014.

O CNJ não diz para o cidadão o que é uma conciliaçáo - procedimento ou método -, mas apenas recomenda fortemente seu uso. $\mathrm{O}$ portal apresenta a figura do conciliador - o "conciliador é a pessoa que faz o papel de facilitador" - sem esclarecer qualquer referencial teórico ou prático de sua atuação. No entanto, garante ao cidadão que o conciliador pode operar de forma prévia à judicialização, os "problemas que afligem" aos cidadãos que buscam o judiciário. Através de frases de incentivo, o website sugere ao cidadão a conciliação como uma solução extraordinária para resolver conflitos de uma forma que nos remete aos canais de televisão especializados em vendas:

Rápida, barata, eficaz e... pacífica! - A conciliação resolve tudo em um único ato, sem necessidade de produçáo de provas (...) e pode ser usada em quase todos os casos: pensão alimentícia, divórcio, desapropriação, inventário, partilha, guarda de menores, acidentes de trânsito, dívidas em bancos e financeiras e problemas de condomínio, entre vários outros (CNJ, 2014).

Esta falha comunicacional no website não é privilégio apenas do CNJ e parece ser um reflexo da implementação desta prática no sistema judiciário como um todo. 
Em pesquisa sobre a aplicação da concicliação no TJRJ, Mello e Baptista (2011) falam da distância entre a proposta em tese e a prática dos tribunais ${ }^{26}$.

A "mediação" irá aparecer apenas em um tópico explicativo da diferença entre a conciliação e a mediação. Ao diferenciar conciliação de mediação, mais uma vez a informação ao leitor acontece em bases superficiais. Neste caso, no entanto, um pouco mais grave, pois a explicação é questionável e pode induzir o cidadão ao erro:

A mediação pode ser mais demorada e até não terminar em acordo, como sempre acontece na conciliaçáo. Mas, mesmo assim, as partes têm considerado a mediação bastante positiva, pois, ao final dos debates, os envolvidos estão mais conscientes e fortalecidos (CNJ, 2014, grifo nosso).

O website informa que toda conciliação culmina em acordo, mas, na sequencia, enfatiza a liberdade do cidadão de aceitar ou não o acordo - um contra senso. E mais adiante, a expressão "Mas, mesmo assim", sugere uma expectativa menor na mediação enquanto procedimento, quando comparado à conciliação.

Ainda nas políticas judiciárias para estímulo às práticas alternativas à adjudicação, encontramos as "Campanhas de Conciliação". Ao clicar, encontramos apenas referências a peças publicitárias ${ }^{27}$. Além das campanhas publicitárias de conciliação, outras estratégias de disseminação das práticas da conciliação que encontramos no website são (1) a premiação "Conciliar é legal" 28 e a "Semana da Conciliação" ${ }^{29}$ e mais recentemente, os "Núcleos de Conciliação", estes últimos amparados na resolução 125 .

\footnotetext{
${ }^{26} \mathrm{Na}$ prática, as “partes” são excluídas desta fase processual pois só precisam estar presentes se há coleta de depoimento pessoal. Caso contrário, os advogados conduzem sozinhos. Mello e Baptista (2011) fazem também uma crítica ao conciliador a partir de entrevistas onde identificam que, pela falta de perspectiva profissional de uma carreira, quem ocupa esta função em geral tem uma segunda intenção, cumprir requisito de tempo de experiência para realizaçáo de concurso público. Em outras palavras, o interesse pelo desempenho de um bom ofício não são prioridade.

${ }^{27}$ Um exemplo do aspecto publicitário das Campanhas de Conciliação é, por exemplo, o link da campanha de 2013 conduzir o leitor as informaçóes de que a campanha que fez uso de camiseta, banner e cartazes, e ainda, utilizou das redes sociais para divulgação. Ao longo do texto, o único telefone de contato que aparece é o de uma assessoria de comunicação.

${ }^{28}$ Premiação lançada pelo CNJ em 2010 para homenagear magistrados e servidores da Justiça que contribuam para a pacificação social. A partir de 2012 essa premiação foi estendida à faculdades de direito e sociedade civil.

${ }^{29}$ Trata-se de um mutirão que visa eliminar centenas de milhares de processos em uma mesma semana.
} 
Como vimos, existem núcleos de mediação criados nos Tribunais com orientação da resoluçáo 125 , bem como cursos de mediaçáo em andamento com parceria com a UNB e chancela do $\mathrm{CNJ}$, no entanto, náo encontramos referências a estas práticas no website, seja no tópico de "acesso à justiça" ou "serviço ao cidadão"30.

\section{Algumas reflexões resultantes desta análise}

Ao longo deste texto, vimos um pouco da transição política e institucional que o judiciário enquanto poder vem passando no Brasil nos últimos anos: exaustáo do modelo liberal, jurídico-legal e (re) aparecimento da linguagem como uma promessa para o encaminhamento de conflitos - mediação e conciliação. Vimos que esta transição acontece a partir de uma perspectiva democrática: é preciso um judiciário "democrático, humanizado e acessivel". Uma visão que não surge de movimentos sociais, mas da própria instituição. As formas alternativas de resolução de conflitos ganham status de política pública nacional a partir da pauta política do $\mathrm{CNJ}$ com a resolução 125 . No entanto, quando analisamos o que este movimento político institucional representou em termos práticos, percebemos a distância entre discurso político legal e o discurso prático virtual. $\mathrm{Na}$ materialização de programas institucionais, orientados para o cidadáo, o $\mathrm{CNJ}$ dá seu exemplo a partir de uma interface que não comunica qualificadamente as próprias práticas. Não há debate, informação qualificada ou democratização de acesso ao CNJ para o cidadão ao qual este serve. A falta de informação e interação com o jurisdicionado para a escolha dos mecanismos que podem gerar celeridade processual fica evidente neste estudo.

Por outro lado, a institucionalização de práticas como a mediaçáo e conciliação conforme comunicada pelo $\mathrm{CNJ}$, pasteuriza seu potencial emancipatorio ao reduzi-la à ferramenta de redução de taxas de congestionamento de processos judiciais. O foco é a instituição. Ao advertir "não ingresse com uma nova ação" e "faça conciliação" sem dialeticamente construir este entendimento com o público, o que temos é uma "agenda comercial" - campanhas, mutiróes e banners. O foco está em convencer o cidadão a fazer uso de uma prática, ainda que ele não saiba exatamente o que seja. Quando isto acontece, as possibilidades emancipatorias correm risco de serem reduzidas à retórica. $\mathrm{O} C \mathrm{CN}$ parece avançar na apropriação política e ideológica de um conceito moderno de judiciário democrático e humanizado. No entanto, a análise do website parece sugerir que ainda há um trajeto

\footnotetext{
${ }^{30}$ Os únicos cursos informados no website são os cursos de formação de instrutores em "conciliação e mediação". A informação é direcionada aos servidores públicos que desejam fazer o curso. Ao clicar nas chamadas para ediçôes desses cursos que tem inicio em 2011, a informação que acessamos é um regulamento de inscrição.
} 
a ser percorrido na aproximação entre a instituição judiciária e a população para quem esta presta serviço. Esta talvez seja a mediação em curso mais desafiadora no judiciário - um diálogo qualificado com a população.

- Rafaela Selem Moreira é Doutoranda do Programa de Pós Graduação em Sociologia e Direito da Universidade Federal Fluminense. E-mail: rafaselem@ig.com.br.

- Roberto Fragale Filho é Professor do Programa de Pós Graduação em Sociologia e Direito da Universidade Federal Fluminense. E-mail: fragale@alternex.com.br.

\section{Referências}

AZEVEDO, André Gomma (Org). Manual de Mediação Judicial. Brasília: Ministério da Justiça/Programa das Naçóes Unidas para o Desenvolvimento - PNUD, 2009.

CHILTON, Stephen; CUZZO, Maria Stalzer Wyant. Habermas's theory of communicative action as a theoretical framework for mediation practice. Conflict Resolution Quarterly, v. 22, n. 3, p. 3-51, Spring 2005.

CNJ. Portal do CNJ. 2014. Disponível em: <http://www.cnj.jus.br/>. Acesso em: 14 jul. 2014.

DAKOLIAS, Maria. O Setor Judiciário Na América Latina E No Caribe Elementos Para Reforma. Washington: Banco $1996 . \quad$ Dundial, em: <http://www.anamatra.org.br/uploads/document/00003439.pdf>. Acesso em: 10 jan. 2015.

DAVIS, Corinne M. Pequenas Causas e Assistência Jurídica: Usos, transformaçóes e adaptaçóes na favela. In: RIBEIRO, Paulo Jorge; STROZEMBERG, Pedro (Orgs.). Balcão de Direitos: Resoluçóes de conflitos em favelas do Rio de Janeiro: imagens e linguagens. Rio de Janeiro: Mauad Editora, 2001. p. 125-153.

FARIA, José Eduardo. Apresentação. In: FARIA, José Eduardo (Org.). Direito e Justiça, a função do judiciário. São Paulo: Editora Ática S.A, 1989. p. 05-15.

FISS, Owen. Um novo processo civil: Estudos Norte-Americanos sobre jurisdição, constituição e sociedade. São Paulo: Editora Revista dos Tribunais, 2004.

HABERMAS, Jürgen. Teoría de la acción comunicativa. I y II. 4a ed. España: Ed. Taurus, 2003.

HOLSTON, James. Cidadania Insurgente. Disjunçóes da democracia na modernidade no Brasil. 1. ed.

São Paulo: Companhia das Letras, 2013.

IBGE. O Setor de Tecnologia da Informação e Telecomunicação no Brasil 2003-2006. Estudos e Pesquisas - Informação Econômica, Rio de Janeiro, n. 11, 2009.

MELLO, Kátia Sento Sé; BAPTISTA, Bárbara Gomes Lupetti. Mediação e conciliação no Judiciário: Dilemas e significados. Revista Dilemas, v. 4, n. 1, p. 97-122, jan.-mar. 2011. 
MENDONÇA, Ângela Hara Buonomo. Mediação Comunitária. Uma ferramenta de Acesso a Justiça? 2005. 176 p. Tese (Mestrado em Ciências Sociais) - Programa de Pós-Graduação em História Política e Bens Culturais, Fundação Getúlio Vargas, Rio de Janeiro, 2006.

MOREIRA, Rafaela Selem. A Mediação de Conflitos como Ferramenta para Construção de uma Democracia Pautada na razão comunicativa. In: XVIII Congresso Nacional do CONPEDI, São Paulo, 2009.

SALES, Lília Maia de Moraes. Justiça e Mediação de Conflitos. Belo Horizonte: Del Rey, 2003.

SALES, Lília Maia de Morais; ANDRADE, Mariana Dionísio de. A mediação de conflitos como efetivo contributo ao Poder Judiciário brasileiro. Revista do Senado, Brasília, v. 48, n. 192, out.-dez. 2011.

Disponível em: <http://www2.senado.leg.br/bdsf/bitstream/handle/id/242928/000936208.pdf?sequence=3>. Acesso em: 20 jan. 2015.

SOUZA NETO, Cláudio Pereira de Souza. Balcão de Direitos, Retórica e Mediação: Notas sobre a Possibilidade de Uma Metodologia Jurídica Própria. In: RIBEIRO, Paulo Jorge; STROZEMBERG, Pedro (Orgs.). Balcão de Direitos: Resoluçóes de conflitos em favelas do Rio de Janeiro: imagens e linguagens. Rio de Janeiro: Mauad Editora, 2001. p. 81-99.

WIKIPEDIA. Conselho Nacional de Justiça. Disponível em: <http://pt.wikipedia.org/wiki/Conselho_Nacional__de_J usti\%C3\%A7a>. Acesso em: 15 ago. 2014.

Texto recebido em 12 de dezembro de 2014. Aprovado em 19 de março de 2015. 
